\title{
Exogenous leptin controls the development of the small intestine in neonatal piglets
}

\author{
J Woliński, M Biernat, P Guilloteau', B R Weström² \\ and R Zabielski \\ The Kielanowski Institute of Animal Physiology and Nutrition, Polish Academy of Sciences, 05-110 Jabłonna, Instytucka 3, Poland \\ ${ }^{1}$ Unité Mixte de Recherches sur le Veau et le Porc, INRA, 35590 Rennes, France \\ ${ }^{2}$ Institute of Cell and Organism Biology, Lund University, Lund, Sweden \\ (Requests for offprints should be addressed to R Zabielski; Email: r.zabielski@ifzz.pan.pl)
}

\begin{abstract}
Leptin, a hormone produced and secreted by adipose tissue, muscles and stomach, is involved in the regulation of adipose tissue mass, food intake and body weight in neonatal animals. It is also produced in the mammary glands and secreted into the colostrum and milk. Since leptin receptors are widely distributed in the small intestine mucosa, the aim of the present study was to investigate the effect of exogenous leptin on the development of the small intestine in neonatal piglets. Male neonatal piglets were fed with sow's milk or artificial milk formula. Every $8 \mathrm{~h}$ the latter received either vehicle or leptin (2 or $10 \mu \mathrm{g} / \mathrm{kg}$ body weight). The animals were either killed after 6 days of treatment and the small intestine sampled for histology and brush border enzyme activities or were tested for marker molecule (Na-fluorescein and BSA)
\end{abstract}

absorption in vivo. Feeding milk formula slowed the maturation of small intestinal mucosa compared with feeding sow's milk. However, after leptin treatment the length of the small intestine was increased, and intestinal villi length, but not crypt size, was reduced compared with controls. The mitotic index was increased and the percentage of vacuolated enterocytes was reduced in the entire small intestine. Enterocyte brush border protease and lactase activities were reduced in the jejunum. Nafluorescein marker molecule absorption did not change but that of BSA was reduced 3.8-fold. In conclusion, exogenous leptin administered in physiological doses reversed the maturation of the small intestinal mucosa to the range found in sow-reared piglets.

Journal of Endocrinology (2003) 177, 215-222

\section{Introduction}

Leptin is a 167 amino acid protein, first discovered in adipose tissue (Zhang et al. 1994) and after that in a wide variety of tissues, including the mammary gland (SmithKirwin et al. 1998, Aoki et al. 1999, Silva \& VandeHaar 1999, Bonnet et al. 2002). Smith-Kirwin and co-workers (1998) demonstrated the biosynthesis of leptin in human placenta and suggested a plausible role of the hormone in foetal growth. After birth, colostrum and milk take over some of the placenta's functions, especially in regard to the delivery of maternal hormones and growth factors to the neonate. This is true also for leptin, which has been identified in human, mouse, rat and pig colostrum and milk (Casabiell et al. 1997, Houseknecht et al. 1997, Aoki et al. 1999, Estienne et al. 2000, Ucar et al. 2000). It is noteworthy that in humans, leptin is present in whole breast milk at 30- to 150-fold higher concentrations than in milk formula (Houseknecht et al. 1997, Smith-Kirwin et al. 1998), and its concentration in breast milk is positively correlated with maternal and/or infant plasma leptin concentrations. Silva and co-workers (1999) showed that leptin is synthesized in the mammary gland and excreted with milk. In contrast, Casabiell and co-workers (1997) demonstrated that leptin is transferred from the circulation to the mammary gland, then without loss of biological activity, to the milk and after that to the infant's stomach and general blood circulation. The biologically active form of the leptin receptor (OB-Rb) (Cioffi et al. 1996, Lee et al. 1996) is widespread, and has been localized in the entire length of the small intestine (Morton et al. 1998). Using immunostaining, Barrenetxe et al. (2002) demonstrated the leptin receptor within the cytoplasm of enterocytes located on both intestinal villi and crypts in the human, rat and mouse small intestine. In human enterocytes, the OB-Rb receptor (long form of the leptin receptor) was also found in the brush border plasma membrane (Barrenetxe et al. 2002).

These studies suggest that 'milk-borne' leptin may play a role in the offspring, although its effect on the development of the neonatal gastrointestinal tract has never been experimentally verified. The aim of the present study was 
to investigate the role of exogenous leptin in the development of the small intestine of neonatal piglets fed artificial milk formula. Development was evaluated in regard to the microscopic structure of the intestinal mucosa, brush border-specific enzyme activities and in vivo intestinal absorption of marker molecules.

\section{Materials and Methods}

\section{Animal experiments}

The experiments and treatments were conducted in compliance with the European Union regulations concerning the protection of experimental animals. The Local Ethics Committee approved the study protocol. A total of 44 male neonatal piglets (Polish Landrace $\times$ Pietrain) from nine different litters were purchased from a commercial pig farm. The average birth weight was $1.60 \pm 0.15 \mathrm{~kg}$. The piglets were delivered healthy and without complications, and were kept with their sows for $24 \mathrm{~h}$, except six of them that were kept with their sows for 7 days (control group of sow-reared piglets (CSR)). Six animals were killed by pentobarbiturate overdose $24 \mathrm{~h}$ after birth, and another six were killed 7 days after birth (CSR), and sampled like those described below. The other 26 animals were installed (initially in groups of four piglets) in the laboratory in a special cage equipped with an 'artificial sow'. The laboratory provided a $12 \mathrm{~h}$ light: $12 \mathrm{~h}$ darkness cycle and an ambient temperature that was decreased from $32{ }^{\circ} \mathrm{C}$ to $28^{\circ} \mathrm{C}$ over the 6 days of the experiment to ensure a comfortable environment for neonatal piglets. At the beginning of each trial, four piglets were kept together for an approximately $12 \mathrm{~h}$ period of adaptation. After that, the piglets were housed individually in a manner providing social contact with each other. Milk-replacer formula for piglets (protein 19.8\%; fat 19.7\%; ash 8.2\%; Milky Farm, Nukamel Olen, Belgium) was distributed to each piglet every $75 \mathrm{~min}$ (20 times per $24 \mathrm{~h}$ ) in equal amounts by means of an artificial sow (Research Centre Foulummodel, Pig's oline; Boss' Produkter a/s, Denmark). The daily amount of milk replacer was calculated on the basis of daily body weight gain and protein intake. Body weight was recorded every morning. Protein intake in neonatal pigs rose gradually from 11.0 to $11.3 \mathrm{~g} / \mathrm{kg}$ body weight during the first 7 days of life. The concentration of protein in milk formula was $20 \%$ of dry matter (V Lesniewska \& M Hedemann, unpublished observations). Sow colostrum and milk, artificial milk formula and plasma blood samples collected from pig neonates were measured for leptin concentration using an RIA kit (Leptin Multi-Species; Linco Research Inc., St Louis, MO, USA). The assay was performed in one run.

Two series of experiments were performed in the laboratory. In the first series, 18 animals were randomly divided into three groups that received either vehicle alone $(5 \mathrm{ml} 0.9 \% \mathrm{NaCl})-$ control group $(n=6)$, leptin
(Leptin Mouse Recombinant; Sigma, St Louis, MO, USA) at a dose of $2 \mu \mathrm{g} / \mathrm{kg}$ body weight - group L2 $(n=6)$, or $10 \mu \mathrm{g} / \mathrm{kg}$ body weight - group L10 $(n=6)$ every $8 \mathrm{~h}$ via a stomach tube. The $\mathrm{pH}$ of the vehicle was $5 \cdot 8$, which is optimal for leptin bioactivity and similar to that of the ingested milk replacer. After 6 days of vehicle or leptin treatment the animals were killed by pentobarbiturate (Vetbutal; Biowet, Poland) overdose, and the gastrointestinal tract was removed for morphometric analysis and tissue sampling. The stomach and pancreas were weighed and the small intestine's weight and length determined. Whole-thickness samples of the duodenum, proximal (25\%), middle (50\%) and distal (75\%) jejunum and ileum were harvested and fixed in Bouin's solution for histological analysis. The corresponding $15 \mathrm{~cm}$ long intestine segments were gently scraped to collect the mucosa for enzyme activity analysis. In the second series, eight piglets were divided into two groups receiving saline (CM, $n=4)$ or leptin at a dose of $10 \mu \mathrm{g} / \mathrm{kg}$ body weight $(\mathrm{LM}, n=4)$ using an identical schedule as in the first series. On day 6 they were implanted with Silastic catheters in the left jugular vein under general halothane anaesthesia, and on the day after, a test of in vivo intestinal absorptive capacity was performed. In the morning, the CM and LM groups received a marker molecule cocktail by a stomach tube. The cocktail contained: $500 \mathrm{mg} / \mathrm{kg}$ BSA (67 kDa, Cat. No. A-4503; Sigma) and $9.4 \mathrm{mg} / \mathrm{kg}$ Na-fluorescein (376 Da; Merck, Darmstadt, Germany). The components were dissolved in $0.9 \% \mathrm{NaCl}$ immediately before administration and given to the pigs in a volume of $4 \mathrm{ml} / \mathrm{kg}$ body weight. For marker molecule analysis, $4 \mathrm{ml}$ venous blood samples were taken just before administration $(0 \mathrm{~h})$ and after $0 \cdot 5,1,2,4,8$ and $24 \mathrm{~h}$. After the last blood sample was taken, the animals were killed by pentobarbiturate overdose. The blood samples were centrifuged at $3000 \mathrm{~g}$ $\left(4{ }^{\circ} \mathrm{C}\right)$ for $15 \mathrm{~min}$ and the plasma harvested and stored frozen $\left(-20^{\circ} \mathrm{C}\right)$ until analysis.

\section{Mucosa histology and laser scanning cytometry (LSC)}

Serial histological sections of $5 \mu \mathrm{m}$ thickness were cut and stained with haematoxylin and eosin for morphometric analysis under a light microscope. After staining, the depth of crypts, length of villi and thickness of the tunica mucosa were measured in the small intestine preparations at a low magnification with a Nikon type 104 (Nikon Corporation, Yokohama, Japan) optical binocular microscope coupled via a camera to a computer. In each slide, 30 well-oriented villi and crypts were measured using Lucia G v4.60 software (Laboratory Imaging Ltd, Prague, Czech Republic). In each slide from the jejunum and ileum, all of the enterocytes in 30 well-oriented villi were analysed for the presence of 'lysosomal vacuoles' (LV) and the percentage of vacuolated enterocytes was calculated (Biernat et al. 1999). In each villi, 20 vacuolated enterocytes were measured for the area of LVs $\left(\mu \mathrm{m}^{2}\right)$ using a 
planimetry feature of the Lucia G v.4.60 software. The mitotic index was estimated in the jejunal crypts by calculating the percentage of mitotic cells in 1000-1200 counted cells (Biernat et al. 1999).

The rate of apoptosis in the mid-jejunum was estimated on the basis of chromatin condensation and DNA content in the nuclei following 7-aminoactinomycin D (7-AAD) staining using LSC (CompuCyte Corp., Cambridge, MA, USA). The fluorescence excitation was provided by a $488 \mathrm{~nm}, 10 \mathrm{~mW}$ argon laser beam. The far-red fluorescence of 7-AAD was measured using a combination of dichroic mirrors and filters transmitting at $>650 \mathrm{~nm}$ (detector offset 2000 and gain 30). For chromatin condensation another parameter was acquired, corresponding to the highest value of DNA-related fluorescence in the cell - the DNA maximal pixel. In the mid-jejunum, the mitotic index to apoptosis ratio was measured.

\section{Brush border enzyme activity}

Brush border enzyme activity was measured in the mucosa scrapings from the proximal, middle and distal parts of the jejunum. The mucosa was scraped off with a microscope slide, and deep-frozen in liquid nitrogen $\left(-80^{\circ} \mathrm{C}\right)$. After thawing, the intestinal mucosa was homogenized in cold distilled water ( $1 \mathrm{~g}$ intestinal mucosa $/ 5 \mathrm{ml}$ distilled water) and centrifuged for $5 \mathrm{~min}$ at $1000 \mathrm{~g}$ at $4{ }^{\circ} \mathrm{C}$. The protein content was then determined as described by Hartree (1972), using BSA as the standard. The activities of aminopeptidase $\mathrm{A}$ and $\mathrm{N}$ were assayed with L-glutamyl$p$-nitroanilide and L-leucyl-p-nitroanilide as substrates respectively (Maroux et al. 1973), and that of dipeptidase IV was assayed with glycyl-L-prolyl-p-nitroanilide (Nagatsu et al. 1976). The resulting enzymatic units (IU) are expressed as $\mu \mathrm{mol} p$-nitroanilide released $/ \mathrm{min}$ at $37^{\circ} \mathrm{C}$. Lactase, maltase and sucrase were determined as described earlier (Dahlquist 1964) with minor modifications.

\section{Marker macromolecule analysis}

The concentrations of marker molecules in the plasma samples from the second series of experiments were analysed according to Nejdfors et al. (2000). The fluorescence of $\mathrm{Na}$-fluorescein was measured in a 96-microwell plate (Nunc, Roskilde, Denmark) by spectrophotofluorometry (CytoFluor 2300; Millipore, Bedford, MA, USA), using a filter set-up of $485 \mathrm{~nm}$ for excitation and $530 \mathrm{~nm}$ for emission. The standards for $\mathrm{Na}$-fluorescein were dissolved in PBS. BSA was quantified by electroimmunoassay (Laurell 1966), using purified BSA diluted in swine serum as a standard and rabbit anti-BSA antibodies (Dako, Glostrup, Denmark). Analysis of the area under the curve (Graph Pad Software v.2·0, San Diego, CA, USA) was performed to compare the marker molecule absorption between CM and LM groups.

\section{Statistical analyses}

The data are expressed as means \pm S.E.M. One-way ANOVA followed by the Tukey post-ANOVA test was used to indicate the statistical differences between the groups in the first series, and the unpaired Student's $t$-test or non-parametric Mann-Whitney test was used to indicate the statistical differences between the groups in the second series (Graph Pad Software v.3.03). In all statistical analysis $P<0.05$ was taken as the level of significance.

\section{Results}

After transporting from the farm, four pig neonates were kept together in one cage for $12 \mathrm{~h}$; at that time (usually within 5-6 h) one of them had taught himself how to eat from the artificial sow. The other piglets soon followed the leader; thus, after separating them into individual cages all piglets ate milk formula distributed by the artificial sow. No differences in appetite between the milk formula-fed (control, CM) and leptin-supplemented (L2, L10, LM) piglets were observed, and all piglets ate all of the milk formula dosed by the artificial sow at once. The concentration of leptin in colostrum was $53 \cdot 7 \pm 15 \cdot 2 \mathrm{ng} / \mathrm{ml}$ in the first portions, $71 \cdot 7 \pm 13.0 \mathrm{ng} / \mathrm{ml} 24 \mathrm{~h}$ after that, and in milk collected on day 7 postpartum it was $25.5 \pm 2.5 \mathrm{ng} /$ $\mathrm{ml}$. In the milk formula samples the concentration of leptin was $20 \cdot 3 \pm 2 \cdot 5 \mathrm{ng} / \mathrm{ml}$. In the milk formula-fed piglets the concentration of leptin in the blood plasma was reduced by about $25 \%$ with respect to sow-reared piglets. Intragastric administration of leptin had no effect on plasma leptin concentration, which in control and L10 piglets equalled respectively $1.81 \pm 0.44$ and $1.41 \pm 0.13 \mathrm{ng} / \mathrm{ml}$.

\section{Body and organ weights}

Neonatal piglets, fed with sow's milk (CSR) between days 1 and 7 of life gained on average $270 \pm 81 \mathrm{~g}$ daily; however, no data on their daily food intake are available. In milk formula-fed piglets the food intake was $96 \pm 13 \mathrm{~g}$ dry matter per day. Milk formula-fed piglets gained less, $84 \pm 15 \mathrm{~g}$ daily, and had a shorter small intestine (jejunum) and lighter pancreas compared with CSR (Table 1). Six days of leptin treatment had no effect on the body weight of the investigated neonatal piglets or on the stomach, liver, or pancreas weights relative to the body weight compared with the control group (Table 1). The length of the jejunum showed a significant increase and that of the ileum a significant reduction in the piglets treated with $10 \mu \mathrm{g} / \mathrm{kg}$ body weight of leptin. The length of the entire small intestine in leptin-treated piglets (L10) was not different from that found in piglets fed with sow's milk (Table 1).

\section{Small intestine morphometry}

The results of histometry analysis are shown in Table 2 . Feeding with milk formula (control) reduced the crypt 
Table 1 Body weight, intestine length and organ weight in sow-reared (CSR), control (C) and leptin-treated (L2, L10) piglets on day 7 of life. Values are means \pm S.E.M. $(n=6)$

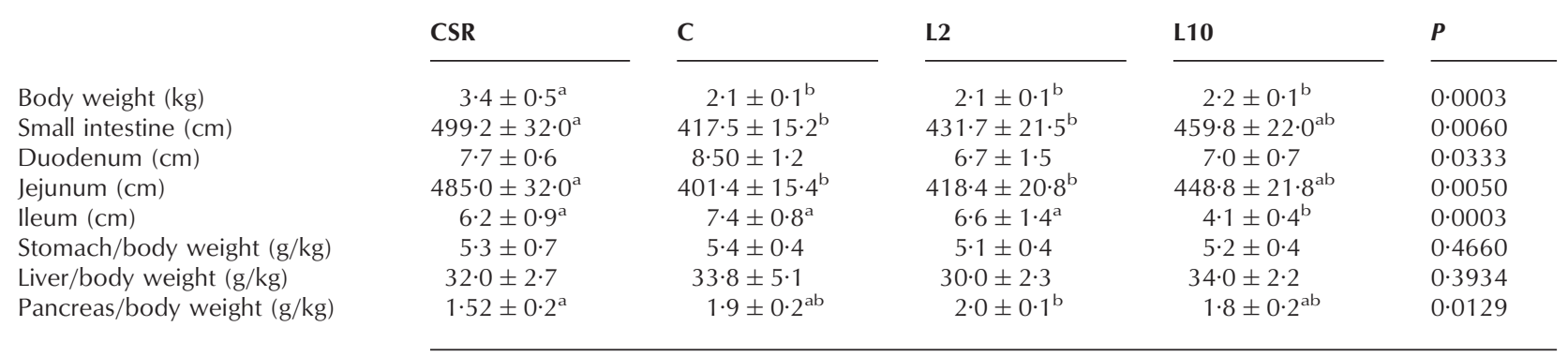

Different letters in a row indicate statistical significance (one-way ANOVA followed by Tukey post-ANOVA test).

depth in the duodenum, reduced the length of villi and thickness of mucosa in the proximal jejunum and increased the length of villi and thickness of mucosa in the ileum compared with natural milk feeding (CSR). Exogenous leptin caused a significant reduction of villi length and correspondingly a reduction in mucosa thickness in the middle and distal jejunum and ileum compared with milk formula-fed control piglets. Although the size of intestinal crypts did not change, the mitotic index was the lowest in the jejunum and ileum in the milk formula-fed group, and the highest in the leptin-supplemented group (Table 2). The apoptotic index analysed using LSC in the mid-jejunum in the sow-reared group (CSR) was $21 \cdot 1 \pm 5 \cdot 0 \%$. In the milk formula-fed (control) and leptin (L10) groups it was respectively $23 \cdot 2 \pm 3 \cdot 0$ and $19 \cdot 7 \pm 1 \cdot 2 \%(P=0 \cdot 069)$. The mitotic index to apoptosis ratio calculated for this segment of the jejunum in the leptin-supplemented group was, however, 1.9-fold higher compared with the control group, and only 1.16-fold higher compared with the CSR group.

In sow-reared piglets (CSR) large LVs were present in the enterocytes only in the distal jejunum and ileum, whereas in the milk formula-fed and leptin-supplemented piglets they were also in the mid-jejunum. However, in the leptin-supplemented group (L10) there were only a few LVs in the jejunum and ileum, and of smaller size compared with the CSR and control groups (Table 2 and Fig. 1).

Table 2 Histological parameters $(\mu \mathrm{m})$, mitotic index (\%), cross-section area of $\mathrm{LV}\left(\mu \mathrm{m}^{2}\right)$ and percentage of vacuolated enterocytes $(\%)$ in sow-reared (CSR), control (C) and leptin-treated (L10) piglets on day 7 of life. Values are means \pm S.E.M. $(n=6)$

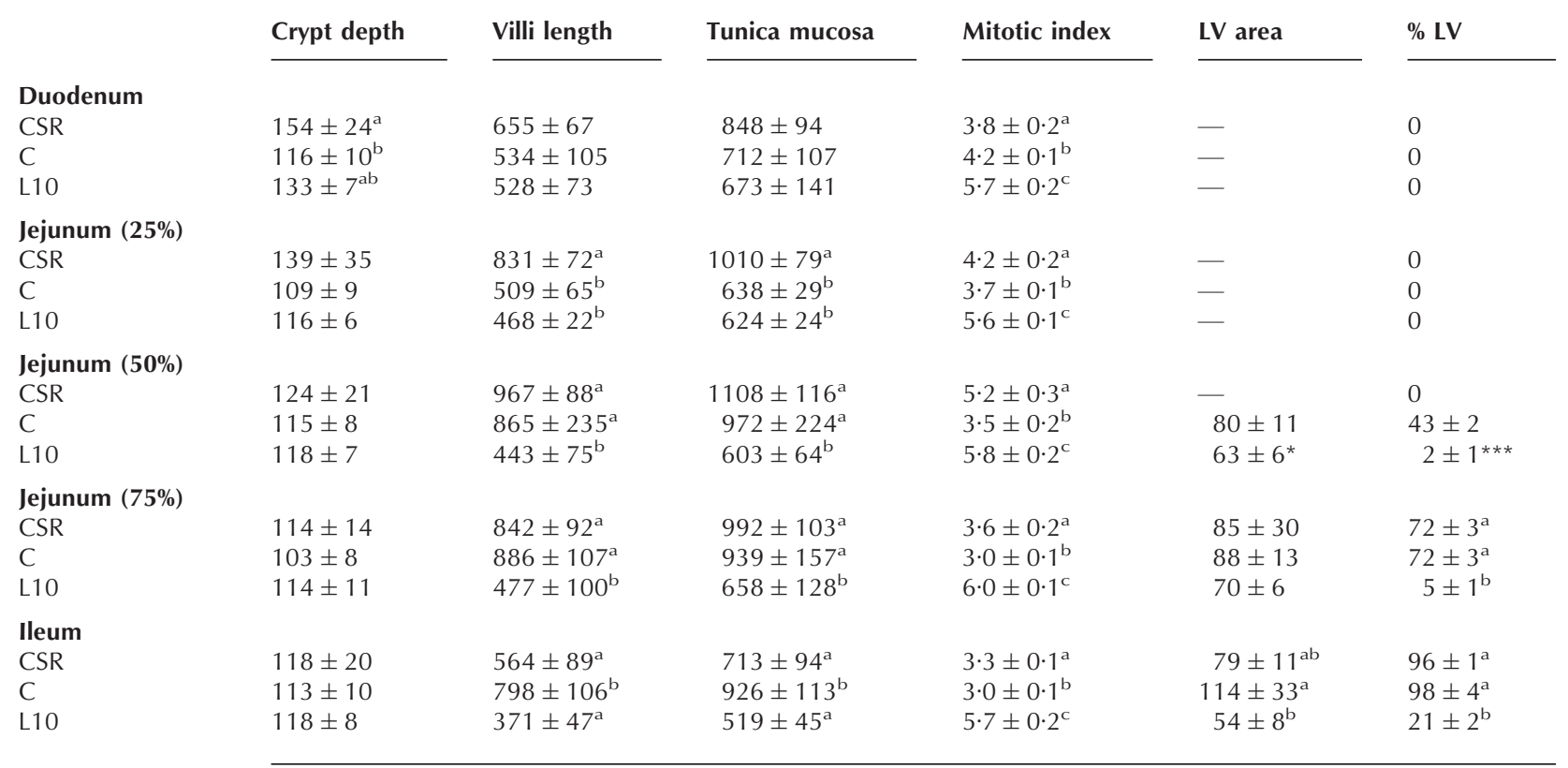

Different letters in columns indicate statistical significance (one-way ANOVA followed by Tukey post-ANOVA test). ${ }^{*} P<0 \cdot 05,{ }^{* * *} P<0 \cdot 001$ (Student's $t$-test followed by Mann-Whitney test). 

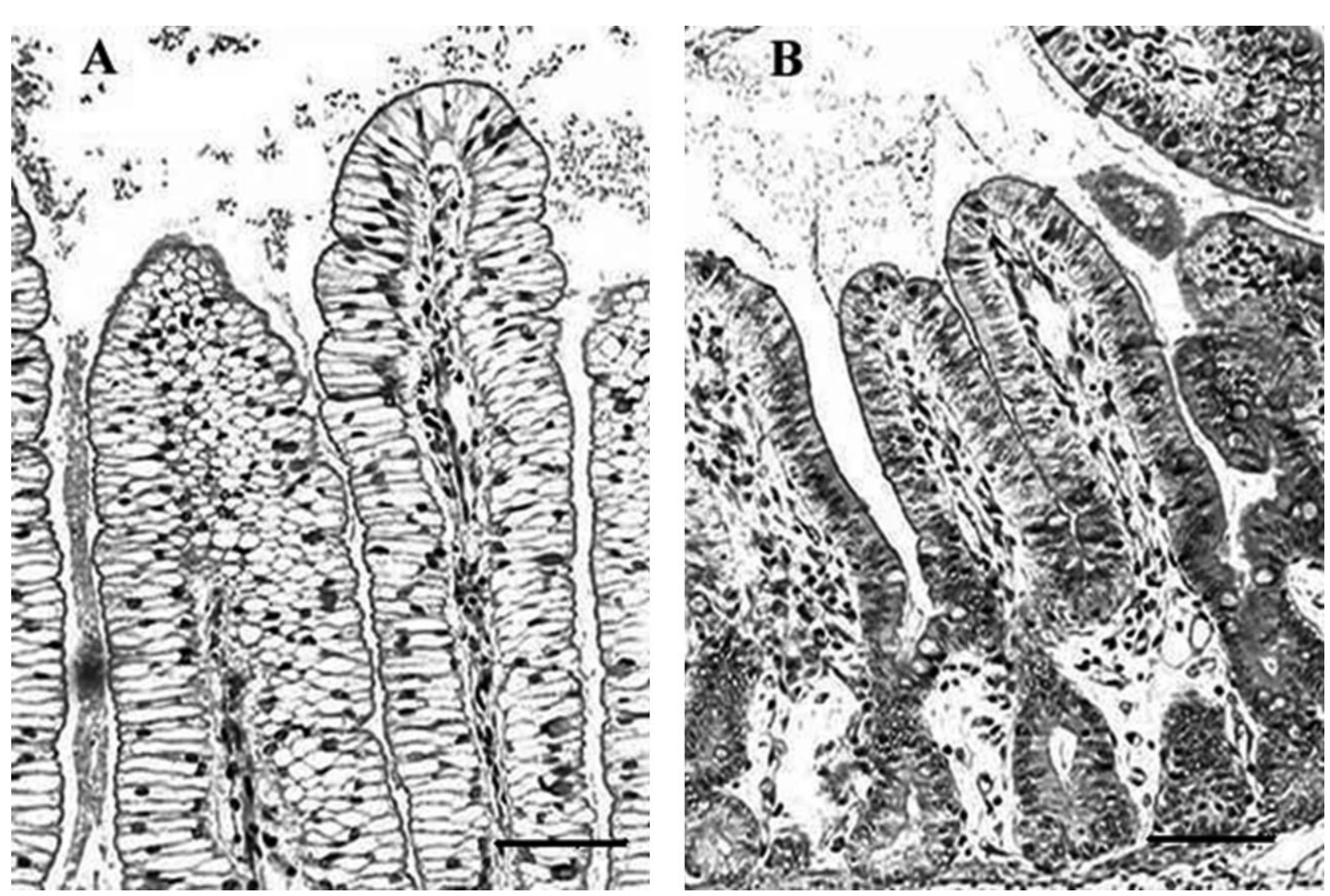

Figure 1 Representative photographs of the villi in the ileum of milk formula-fed (A) and leptin-supplemented (B) piglets. Note that the villi in the milk formula-fed piglets are much longer than those in the leptin group, and almost all enterocytes in the milk formula-fed piglets contain large LVs in contrast to the leptin-treated group. Haematoxylin and eosin staining. Scale bars $=100 \mu \mathrm{m}$.

\section{Brush border enzyme activities}

In sow-reared piglets, the activity of the examined brush border enzymes (aminopeptidase A and N, dipeptidase IV, lactase, maltase and sucrase), showed normal dynamic changes during the first week of life (data not shown) related to development. Compared with sow's milk, feeding milk formula resulted in elevation in aminopeptidase $\mathrm{A}$ and $\mathrm{N}$, dipeptidase IV and lactase activity and reduction in lactase, maltase and sucrase in the respective segments of the jejunum (Table 3). Notably, in leptintreated piglets there was a general trend towards recovery of aminopeptidase $\mathrm{A}$ and $\mathrm{N}$ and dipeptidase IV activity to levels observed in sow-reared piglets, the activity of lactase in the mid- and distal jejunum was further decreased below the activity present in sow-reared piglets (Table 3). The activity of maltase and lactase in the proximal and distal jejunum of leptin-supplemented piglets was not different from that in piglets receiving sow's milk (CSR) or milk formula (controls) whereas in the mid-jejunum it was as low as in the milk formula-fed group (Table 3). The effects of leptin were dose-dependent (data not shown). The activity of maltase was reduced only in the distal jejunum in leptin-treated piglets compared with the controls. Sucrase activity did not show any differences between the leptin-treated animals and controls.

\section{Marker molecule absorption}

After administration of marker molecules, the blood levels of the markers increased in both groups $(P<0 \cdot 01)$. The peak blood plasma concentration differed between the marker molecules in a size-dependent manner, and the peaks were seen after $30 \mathrm{~min}$ for $\mathrm{Na}$-fluorescein and after $8 \mathrm{~h}$ for BSA (Fig. 2). Area under the curve analysis revealed that plasma levels for $\mathrm{Na}$-fluorescein did not differ significantly between the two groups whilst that of BSA was $3 \cdot 8$-fold reduced $(P=0 \cdot 016)$ in the leptin group compared with the control. This indicates less intestinal absorption of large-size molecules in the leptin-treated piglets.

\section{Discussion}

Our studies demonstrate for the first time that leptin present in colostrum and milk may be important for 
Table 3 Brush border enzyme activity ( $\mu \mathrm{mol} / \mathrm{min}$ per g mucosa) in sow-reared (CSR), control (C) and leptin-treated (L10) piglets on day 7 of life. Values are means \pm S.E.M. $(n=6)$

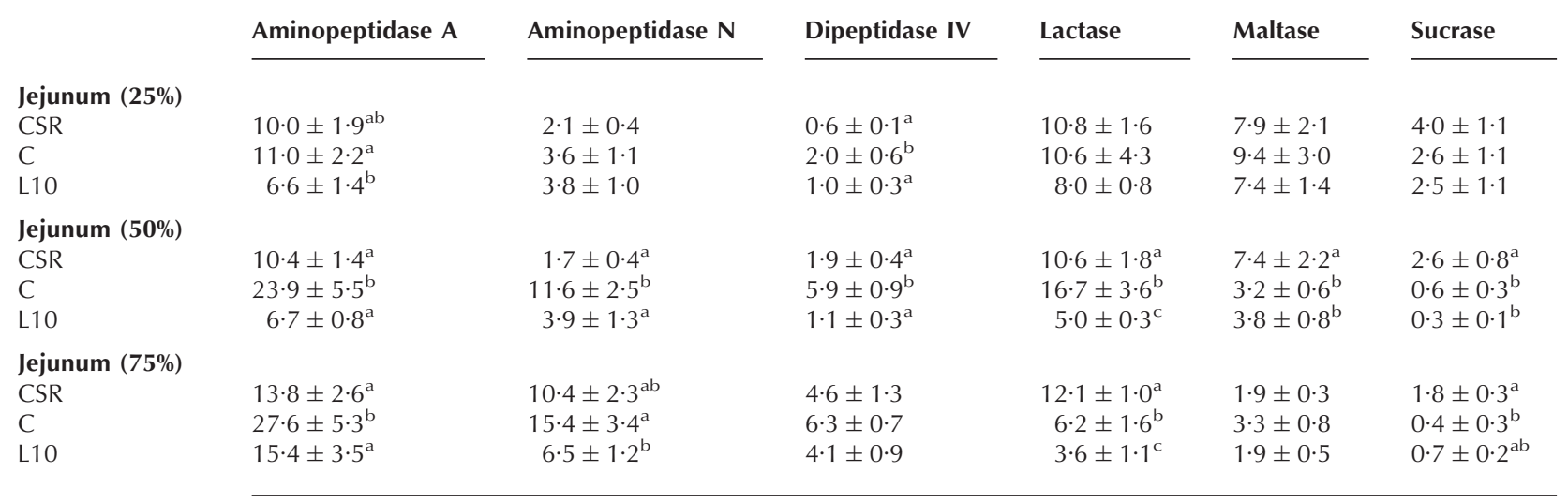

Different letters in columns indicate statistical significance (one-way ANOVA followed by Tukey post-ANOVA test).

controlling the development of small intestine structure and function in neonatal piglets. Importantly, the clear-cut effects of leptin supplementation on intestinal mucosa morphometry, presence of LVs in the enterocytes, proliferation of mucosa epithelial cells, enterocyte brush border enzyme activities and marker molecule absorption were observed following doses of leptin that can be considered physiological.

The concentrations of leptin in sow's milk, and in the blood plasma in piglets, correspond to those previously reported (Estienne et al. 2000), although no data on leptin in sow colostrum and milk at the very beginning of lactation are available. In our study, the concentration of leptin in milk formula, being roughly one-third of that in the colostrum and four-fifths of that in milk, was much higher than previously reported for human milk formula (Houseknecht et al. 1997, Resto et al. 2001). The difference is most probably related to the applied technologies of producing milk formula (Resto et al. 2001). Thus, the higher dose of leptin in our study was sufficient to supplement the neonates in the colostrum period, and the lower dose was sufficient thereafter. Unfortunately, we did not have a chance to access the sows for additional sampling to get more precise kinetics of the leptin concentration in colostrum and milk. In milk formula-fed piglets, plasma leptin did not increase in response to enteral administration of leptin, which may suggest that: (i) leptin is not transferred from the gut into the circulation, which is in contrast to the findings in suckling rats by Casabiell et al. (1997), and (ii) the effects observed in the present study depend on leptin receptors localized in the intestinal mucosa (Morton et al. 1998, Barrenetxe et al. 2002).

We observed a reduction in the body weight of artificially reared vs sow-reared piglets; however, in contrast to previous studies in neonatal rats (Yuan et al. 2000), we did not observe body weight reduction following leptin treatment. This can be related to either the much higher doses of leptin applied and/or different route of leptin administration (i.p.) in the rat study. Possibly, the lack of differences in the body weight between milk formula-fed and leptin-supplemented piglets in our study could also be related to similar intake of milk formula in both groups. Nevertheless, we postulate that body weight regulation is rather not a direct target for milk leptin. Earlier studies suggested that leptin can restrict body energy
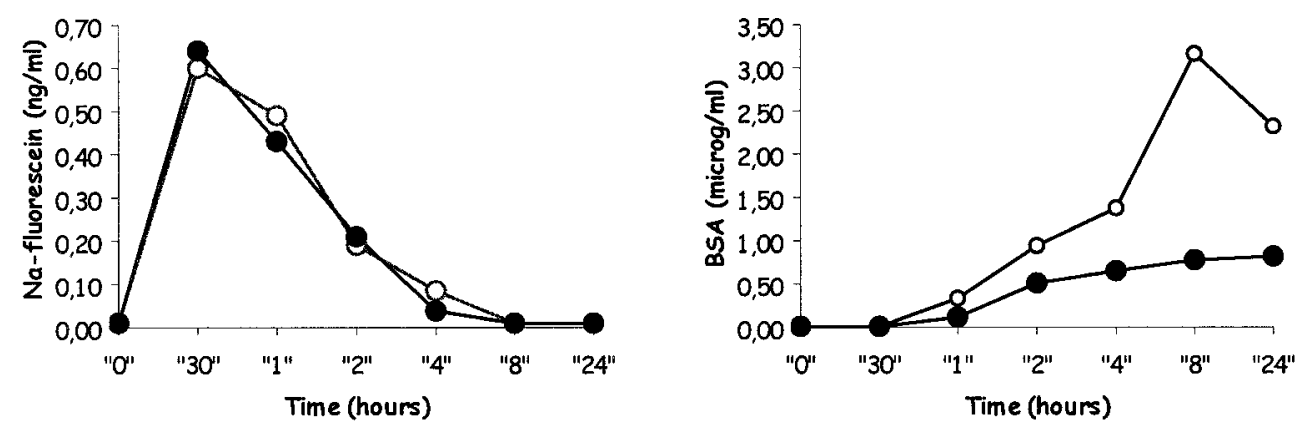

Figure 2 Mean blood plasma levels of marker molecules, Na-fluorescein and BSA during $24 \mathrm{~h}$ after marker gavage feeding to milk formula-fed $(O ; n=4)$ and leptin-treated $(0 ; n=4)$ neonatal piglets. 
accumulation indirectly through a local mechanism in the small intestine controlling the absorption of nutrients (Lostao et al. 1998, Morton et al. 1998) or intestinal motility (Woliński et al. 2001). Lostao et al. (1998) demonstrated that leptin has a rapid inhibitory effect on $\mathrm{D}$-galactose uptake in the rat intestinal mucosa in vitro. In the same year, Morton et al. (1998) showed that leptin can reduce the transcription of genes responsible for apolipoprotein biosynthesis (APO-AIV) in the enterocytes in mouse jejunum in response to olive oil administration. Correspondingly, in the present in vivo study we observed marked activity reduction of all examined brush border enzymes (except sucrase) in leptin-supplemented piglets. It should be borne in mind, however, that in contrast to natural feeding, milk formula enhances the activity of aminopeptidases and dipeptidase IV, and leptin supplementation depressed their activity to the level seen in the sow-reared piglets. Recently, we have shown that repetitive intragastric administration of leptin influences in vitro small intestine contractile activity (Woliński et al. 2001) thus revealing a possible effect of leptin on digesta passage. Leptin increased the spontaneous and acetylcholine-stimulated activity of the duodenum and reduced the activity of the jejunum (Wolinski et al. 2001).

Replacement of sow's milk with milk formula inhibits the growth of the small intestine as well as slows the maturation of the intestinal mucosa as evidenced by low mitotic index, abundance of vacuolated enterocytes in the mid-jejunum and high lactase and peptidase activities. Enteral supplementation with leptin in part reverses these effects. Namely, leptin selectively and dose-dependently increases the length of the small intestine, reduces the thickness of intestinal mucosa by decreasing the height of villi, and significantly reduces the activity of brush border lactase and proteases, regarded as enzymatic markers of gut maturation (Henning 1987, Klein 1989). Stem cell proliferation in the intestinal crypts is enhanced and simultaneously cell apoptosis slightly reduced, thereby the mitotic index to apoptosis ratio becomes similar to that in sow-reared piglets. These effects are consistent with previous immunocytochemical studies (Barrenetxe et al. 2002) showing the presence of leptin receptors in the mucosa on the entire length of the small intestine. Small numbers of LVs in the jejunum and ileum following leptin-supplementation together with an increased mitotic index imply that the irreversible process of replacing foetal-type enterocytes with adult-type ones (Baintner 1994) has been accelerated (Biernat et al. 1999, Radberg et al. 2001). The decrease in the endocytosis rate due to the presence of adult-type enterocytes may explain the sharp reduction in BSA absorption in leptin-supplemented piglets in the present study (Smith \& Peacock 1980). No difference in the absorption of the inert and passively transported small-size molecule (Na-fluorescein) suggests that functionally the intestinal absorptive area is not restricted following leptin supplementation.
In conclusion, feeding neonatal piglets with milk formula slows the maturation of the small intestinal mucosa, and exogenous leptin given into the stomach (in a range that is present in colostrum and milk) may reverse the process as evidenced by morphological and functional studies.

\section{Acknowledgements}

We thank Maria Bąbelewska, Véronique Romé, Inger Matson, Małgorzata Świtońska and Marta Jurkowska for technical assistance. This work was supported by grants from the State Committee for Scientific Research (KBN, Poland, grant No. 3 P06D 047 22), POLONIUM program (Poland and France) and PECO-NEI (France).

\section{References}

Aoki N, Kawamura M \& Matsuda T 1999 Lactation-dependent down regulation of leptin production in mouse mammary gland. Biochimica et Biophysica Acta 1427 298-306.

Baintner K 1994 Demonstration of acidity in intestinal vacuoles of the suckling rat and pig. Journal of Histochemistry and Cytochemistry 42 231-238.

Barrenetxe J, Villaro AC, Guembe L, Pascual I, Muñoz-Navas M, Barber A \& Lostao MP 2002 Distribution of the long leptin receptor isoform in brush border, basolateral membrane, and cytoplasm of enterocytes. Gut $\mathbf{5 0}$ 797-802.

Biernat M, Zabielski R, Sysa P, Sosak-Świderska B, Le Huerou-Luron I \& Guilloteau P 1999 Small intestinal and pancreatic microstructures are modified by an intraduodenal CCK-A receptor antagonist administration in neonatal calves. Regulatory Peptides 85 77-85.

Bonnet M, Gourdou I, Leroux C, Chilliard Y \& Djiane J 2002 Leptin expression in the ovine mammary gland: putative sequential involvement of adipose, epithelial and myoepithelial cells during pregnancy and lactation. Journal of Animal Sciences 80 723-728.

Casabiell X, Pineiro V, Tome MA, Peino R, Dieguez C \& Casanueva FF 1997 Presence of leptin in colostrum and/or breast milk from lactating mothers: a potential role in the regulation of neonatal food intake. Journal of Clinical Endocrinology and Metabolism 82 4270-4273.

Cioffi JA, Shafer AW, Zupancic TJ, Smith-Gbur J, Mikhail A, Platika D \& Snodgrass HR 1996 Novel B219/OB receptor isoforms: possible role of leptin in hematopoiesis and reproduction. Nature Medicine 2 585-589.

Dahlquist A 1964 Assay of intestinal disaccharidases. Scandinavian Journal of Laboratory Investigation 44 169-172.

Estienne MJ, Harper AF, Barb CR \& Azain MJ 2000 Concentrations of leptin in serum and milk collected from lactating sows differing in body condition. Domestic Animal Endocrinology 19 275-280.

Hartree EF 1972 Determination of protein: a modification of the Lowry method that gives a linear photometric response. Annals of Biochemistry 48 422-427.

Henning SJ 1987 Functional development of the gastrointestinal tract. In Physiology of the Gastrointestinal Tract, edn 2, pp 285-300. Ed. LR Johnson. New York: Raven Press.

Houseknecht KL, McGuire MK, Portocarrero CP, McGuire MA \& Beerman K 1997 Leptin is present in human milk and is related to maternal plasma leptin concentration and adiposity. Biochemical and Biophysical Research Communications 240 742-747. 
Klein RM 1989 Small intestine cell proliferation during development. In Human Gastrointestinal Development, pp 367-394. Ed. E Lebendhal. New York: Raven Press.

Laurell CB 1966 Quantitative estimation of proteins by electrophoresis in agarose gel containing antibodies. Annals of Biochemistry $\mathbf{1 5}$ $45-52$.

Lee GH, Proenca R, Montez JM, Carroll KM, Darvishzaded JG, Lee JI \& Friedman JM 1996 Abnormal splicing of the leptin receptor in diabetic mice. Nature 379 632-635.

Lostao MP, Urdaneta E, Martinez-Anso E, Barber A \& Martinez JA 1998 Presence of leptin receptors in rat small intestine and leptin effect on sugar absorption. FEBS Letters 423 302-306.

Maroux S, Louvard D \& Baratti J 1973 The aminopeptidase from hog intestinal brush border. Biochimica et Biophysica Acta 321 282-295.

Morton NM, Emilsson V, Liu YL \& Cawthorne MA 1998 Leptin action in intestinal cells. Journal of Biological Chemistry 273 26194-26201.

Nagatsu T, Hino M, Fuyamada H, Hayakawa H, Sakakibara T, Nakagawa Y \& Takemoto T 1976 New chromogenic substrates for $\mathrm{X}$-prolyl dipeptidyl-aminopeptidase. Annals of Biochemistry $\mathbf{7 4}$ 466-476.

Nejdfors P, Ekelund M, Jeppsson B \& Weström BR 2000 Mucosal in vitro permeability in the intestinal tract of the pig, the rat, and man: species and region related differences. Scandinavian Journal of Gastroenterology 35 501-507.

Radberg K, Biernat M, Linderoth A, Zabielski R, Pierzynowski SG \& Westrom BR 2001 Enteral exposure to crude red kidney bean lectin induces maturation of the gut in suckling pigs. Journal of Animal Science 79 2669-2678.

Resto M, O'Connor D, Leef K, Funange V, Spear M \& Locke R 2001 Leptin levels in preterm human breast milk and infant formula. Pediatrics 108 E15.
Silva LFP \& VandeHaar MJ 1999 Role of leptin in mammary cell proliferation. South African Journal of Animal Science 29 300-301.

Smith MW \& Peacock MA 1980 Anomalous replacement of foetal enterocytes in the neonatal pig. Proceedings of the Royal Society of London. Series B 206 411-420.

Smith-Kirwin SM, O'Connor DM, De Johnston J, Lancey ED, Hassink SG \& Funanage VL 1998 Leptin expression in human mammary epithelial cells and breast milk. Journal of Clinical Endocrinology and Metabolism 83 1810-1813.

Ucar B, Kirel B, Bor O, Kilic FS, Dogruel N, Aydogdu SD \& Tekin N 2000 Breast milk leptin concentrations in initial and terminal milk samples: relationships to maternal and infant plasma leptin concentrations, adiposity, serum glucose, insulin, lipid and lipoprotein levels. Journal of Pediatric Endocrinology and Metabolism 13 149-156.

Woliński J, Śeniewska V, Biernat M, Bąbelewska M, Korczyński W \& Zabielski R 2001 Exogenous leptin influences gastrointestinal growth and in vitro small intestinal motility in neonatal piglets preliminary results. Journal of Animal Feed Science 10 (Suppl 2) 249-254.

Yuan CS, Attele AS, Zhang L, Lynch JP, Xie JT \& Shi ZQ 2000 Leptin reduces body weight gain in neonatal rats. Journal of Pediatric Research 48 380-383.

Zhang Y, Proenca R, Maffei M, Barone M, Leopold I \& Friedman JM 1994 Positional cloning of the mouse obese gene and its human homologue. Nature 372 425-432.

Received 12 November 2002
Accepted 28 January 2003 